death throw some light on this matter. The development of the computer is tending to strangle mathematical thinking among all but the brightest of its users: so one should not be surprised that the computational efficiency of Chinese mathematics tended to inhibit mathematical inventiveness except in the case of brilliant individuals not part of the State's official mathematical bureaucracy. Ch'in Chiu-shao (probably 1202-1261) was one of four such now known to have lived, and worked independently, within half a century. The Shu-Shu chiu-chang is his mathematical legacy-a treatise with problems and answers intended for practical use. Ch'in, a soldier of fortune and administrator, was a colourful and dubious character who will doubtless, when Chinese mathematics is better known in the West, be included in the gallery of such characters with, for instance, such old friends as Cardano and Galois. The treatise is in nine chapters: apparently a significant structure already used in the Ch'iu-chang suan-shu, the standard textbook which in Ch'in's time had already been in use for about a thousand years (less than the time during which Euclid dominated the West!). The contents of Ch'in's book are in many ways similar to the earlier one, but the problems are harder and the fruit of a considerable individual development. But there are some things not to be found in the earlier work. For instance an algorithm for solving the so-called Chinese Remainder Problem (for which Ch'in is at present best known) is the most important. There is also what Dr Libbrecht, doubtless correctly, takes as clear evidence that Ch'in had completely anticipated Horner's method for the solution of equations. Ch'in was apparently so pleased with this method that he deliberately and unnecessarily complicated the solution of one problem in order to demonstrate his virtuosity with an equation of the (unnecessarily high) tenth degree.

Ch'in's book was intended, as the conventions of Chinese mathematics at the time required, as a practical treatise and not as a mathematical text as we know it: it was rather a cookery book, but the recipes were subtle and based on much deeper mathematical thinking than was expressly used in the text. It is for this reason that Dr Libbrecht's research into the book and its background is so valuable. At first sight Libbrecht's book is not an attractive work: it is written as a serious and scholarly study, not for easy reading, but to serve as a start for the accumulation of the knowledge necessary to write a more easily read work. But the book grows on one with deeper acquaintance; its integrity and thoroughness are totally convincing. Clearly Dr Libbrecht's second career as an ori- ental scientific historian (his first was as a teacher of mathematics) is destined to be brilliant and rewarding. The chapter on the socioeconomic information to be derived from Ch'in's book raises high hopes of interesting future developments.

D. B. SсотT

\section{Sussex replies to Rome}

Thinking about the Future: a Critique of the Limits to Growth. Edited by H. S. D. Cole, C. Freeman, M. Jahoda and K. J. R. Pavitt. Pp. 218. (Chatto and Windus (Sussex University): London, 1973.) $£ 3.00$.

$\mathrm{H}_{\text {AS }}$ the development of the energy crisis in the past few months strengthened the argument of Meadows's Limits to Growth, and weakened the trenchant critique of it, Thinking about the Future, by the University of Sussex Science Policy Research Unit team?

The fact that oil reserves are finite has no direct bearing on the Arab use of the oil weapon. It has depended simply on Arab states controlling a proportion of existing production capacity large enough to control the market. The long lags in exploration and drilling and the provision of transport elsewhere has made their action effective in the short term. It has at a stroke, and by design, raised oil prices to the level where as Surrey and Bromley point out in chapter 8, alternative sources of energy become economic. They further remarked, writing early in 1973, "In addition to the political uncertainties surrounding the future of Middle Eastern oil, some of the small Arab states which are large oil producers may decide to conserve their oil reserves until prices rise, rather than accumulating large foreign exchange reserves which are subject to depreciation by inflation and major currency re-alignments".

Peccei, the founder of the Club of Rome which sponsored Limits to Growth, has said that the political factors omitted from the study exacerbate the problem, and these political factors have brought forward the threat of doomsday. But it is equally possible to argue that political factors, as one aspect of the flexibility of human response, have brought forward action on energy supplies in time to deal with supply limitations before they became physically acute. Politics, for all its frustrations, can make society more adaptive than its dynamic systems model, not less.

Likewise within the United Kingdom, whatever the political and economic consequences of the miners' industrial action in the short term, the long term effect can be to secure a more even distribution of wealth and power within one industrial society, thus averting the build-up of greater tensions in the future.

This is not to argue that all is for the best in the best of all possible worlds. But it does raise the question whether on population, food, resources, and pollution The Limits to Growth addressed the right problems at all.

The Sussex team, taking The Limits to Growth at its own valuation, reviews the evidence used and the structure of the model, and concludes they do not justify the conclusions drawn. As a bonus they put Limits in its ideological perspective, against the background of the history of economic thought, the movements of environmentalism and technocracy, and the processes of social change. On evidence and ideology the critique is strong. Experts in particular fields will disagree about the realism of some of the assumptions tried by the Sussex team but they will also criticise those made by Meadows. On the methodology of modelling systems of uncertain, tenuous and changing structure however, the Sussex critique is less sure footed. The Limits of Growth is deficient in having ignored the hard won experience of econometrics, stochastic estimation and control theory, and more general adaptive systems. Forrester and Meadows quite fairly argue that this systems apparatus as it stands cannot draw conclusions from the sparse information available on world environmental problems. But combined with a perception of the real worldMeadows's or anyone else's-it does give a more realistic approach to practical policy making than does the crudities of "systems dynamics", which is no more than the solution of simultaneous dynamic equations. The reason for this is that a wider systems theory illuminates the behaviour of indeterminate systems partially controlled with partial knowledge of system behaviour.

The Sussex critique does not touch this problem of adaptive behaviour beyond pointing to other factors in social change. There are these other factors, but their effect manifests itself in the indeterminacy, not the incoherence, of physical systems when viewed as systems on their own. But the physical systems are important enough to warrant the fullest analysis. For example the Sussex team is well equipped to analyse the evidence on the time lags and uncertainty in industrial innovation, a crucial factor in the ability of industrial society to adapt and survive. Perhaps without the inhibitions of criticising other work, but stimulated by the courage, even the sheer impudence, of The Limits of Growth, the Sussex team will contribute further to the vast task of building a genuine discipline of social systems analysis.

J. W. BRAY 